\title{
Crystalline Lens Subluxation Following Blunt Head Trauma
}

\section{Luxação do Cristalino Após Traumatismo Cranioencefálico Contuso}

Lucas Koenig OLM ${ }^{1}$, Felipe Welter LANGER ${ }^{1}{ }^{1}$, Carlos Jesus HAYGERT ${ }^{1}$ Acta Med Port 2020 Oct;33(10):692-692 - https://doi.org/10.20344/amp.12418

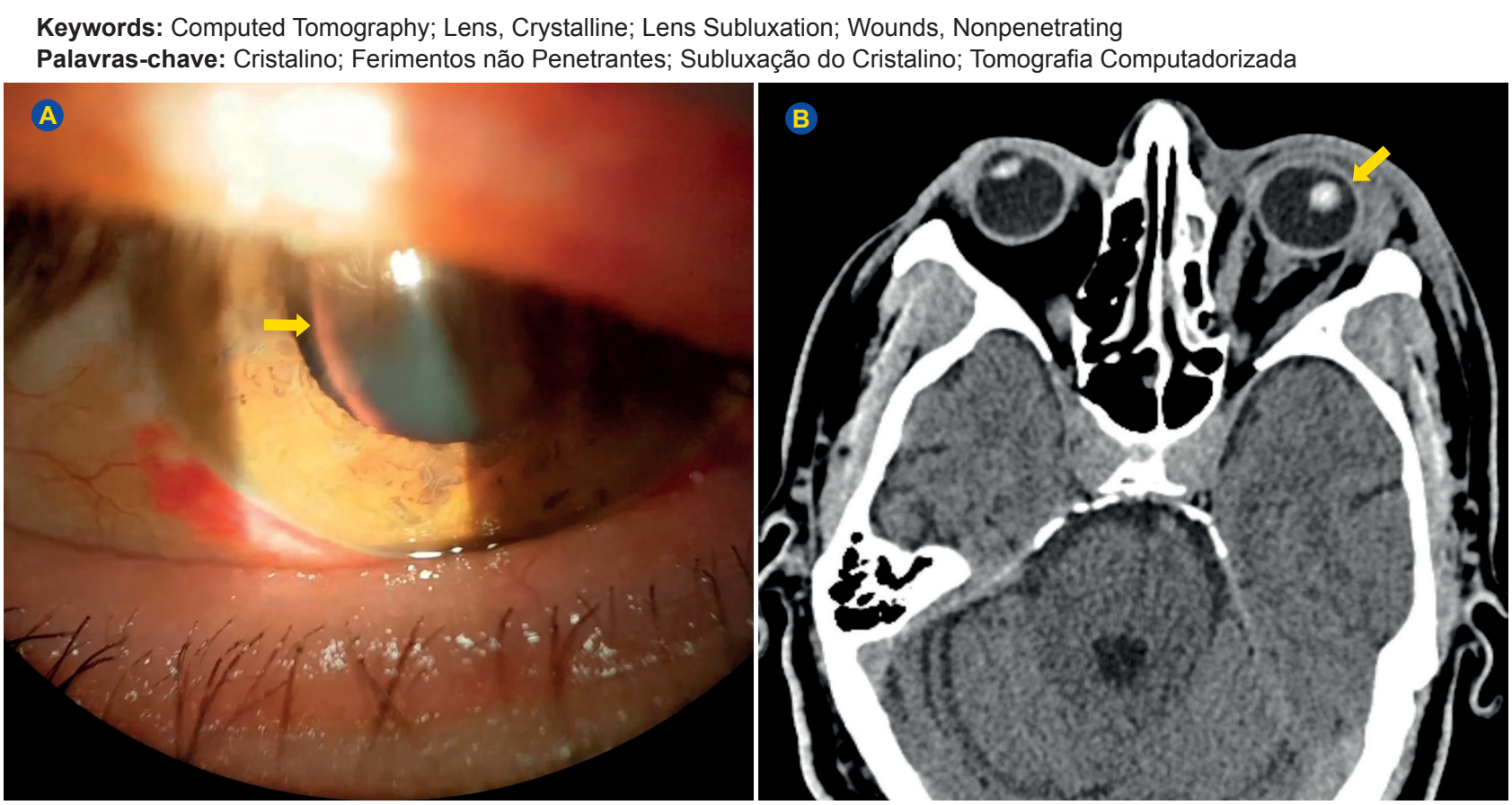

Figure 1 - Slit lamp examination (A) and head computed tomography scan (B, arrow) revealed posterior subluxation of the crystalline lens in the left eye

A 40-year-old man was referred to the emergency department after being hit on the head with a glass bottle during a robbery. He complained of left-sided ocular pain and blurred vision that worsened when lying down. Physical examination revealed periorbital swelling, left-sided ptosis, and normal extraocular movements. Slit lamp examination revealed a small subconjunctival hemorrhage and a mobile lens (phacodonesis) in the left eye (Fig. 1A). Head computed tomography (CT) revealed posterior subluxation of the left crystalline lens (Fig. 1B). The patient was promptly referred for surgical correction of the subluxated lens.
Lens subluxation is a rare complication of head trauma. Blunt orbital trauma can generate anteroposterior eye expansion and tearing of the zonule fibers, which attach the crystalline lens to the ciliary body, leading to partial or complete lens luxation following head injuries. ${ }^{1}$ Management of lens subluxation typically involves surgical lensectomy and intraocular lens implantation. ${ }^{1-3}$ Appendix 1 (see Appendix_01: https://www.actamedicaportuguesa.com/revista/index.php/amp/article/view/12418/Appendix_01-Video.mp4) contains the full video of the intervention.

PROTECTION OF HUMANS AND ANIMALS: The authors declare that the procedures were followed according to the regulations established by the Clinical Research and Ethics Committee and to the 2013 Helsinki Declaration of the World Medical Association.

DATA CONFIDENTIALITY: The authors declare having followed the protocols in use at their working center regarding patients' data publication.

INFORMED CONSENT: Obtained.

FUNDING SOURCES: This study received no specific grant from any funding agency in the public, commercial, or not-for-profit sectors.

\section{REFERENCES}

1. Lee S, Hayward A, Bellamkonda VR. Traumatic lens dislocation. Int J Emerg Med. 2015;8:16.

2. Rankin JK, Pineda R. Traumatic in-the-bag intraocular lens subluxation. Int Ophthalmol Clin. 2013;53:11-21.

3. Salehi-Had H, Turalba A. Management of traumatic crystalline lens subluxation and dislocation. Int Ophthalmol Clin. 2010;50:167-79.

\footnotetext{
1. Department of Radiology and Imaging Diagnosis. Universidade Federal de Santa Maria. Rio Grande do Sul. Brasil. $\bowtie$ Autor correspondente: Felipe Welter Langer. felipewlanger@gmail.com

Recebido: 06 de junho de 2019 - Aceite: 19 de julho de 2019 | Copyright @ Ordem dos Médicos 2020
} 